\title{
ASSESSMENT AND TOPICAL TREATMENT OF LESIONS OF FOOT AND MOUTH DISEASE IN CATTLE
}

\author{
N.A. MISK *; T.N. MISK ${ }^{* *}$ and H.Z. RATEB *** \\ * Department of Veterinary surgery, Anaesthesiology and radiology. Faculty of Veterinary Medicine, Assiut University, \\ Assiut, Egypt. \\ ** Department of Veterinary surgery, Anaesthesiology and radiology. Faculty of Veterinary Medicine, Sadat City University, \\ EI-Menofia, Egypt. \\ ${ }^{* * * *}$ Department of Veterinary Medicine. Faculty of Veterinary Medicine, Assiut University, Assiut, Egypt.
}

\section{ABSTRACT}

Received at:16/3/2015

Accepted: 14/4/2015
The present study was carried out on a total number of 1106 cattle (females $=935$ and males $=171$ ) of an age varied between one year and eleven years. Animals were presented to the clinic within a range of 10 days of infection with different lesions of FMD outbreak occurred at April 2012 at Beni-Suef province, Egypt. The aim of the present study is to describe different lesions of foot and mouth disease (FMD) in cattle. The location and frequency of occurrence of lesions were recorded. Topical and systemic treatment was discussed as an alternative policy for control of FMD lesions in endemic countries. The main lesions of the affected cases were recorded in the dental bad (1053), tongue (1020), and inner aspect of the lower lip (713). A moderate number of lesions were recorded on the gum of lower jaw (318), coronary band and interdigital space (518) and teats (303). Lesions were seen in small number of cases on the muzzle (104), nostrils (17), and hard palate (15). Recovery of all lesions was obtained within 3-10 days with variable degree of scar tissue formation. Slight teat dysfunction and mastitis was supervene in 33 cases. Slight degree of lameness due to thimbling of the claws was recorded in 220 animals. Early management of FMD lesions decreases the economic losses and speeds returning of the animal to normal condition.

Key Words: Topical treatment, FMD, Cattle, Beni-Suef province, Egypt.

\section{INTRODUCTION}

Foot and mouth disease (FMD) is a severe highly contagious disease of cattle, sheep, goats, pigs and other cloven-hooved ruminants (Davies 2002). The disease is characterized by an acute febrile reaction, off food, profuse salivation and formation of blister-like lesions (vesicles) followed by erosion on the tongue and lips, on the teat and between hooves, reduction of milk production, mastitis and infertility. Most affected animals recover but the disease leaves them debilitated (Alexandersen, Zhang et al.,2003).

In countries like Great Britain, the accepted policy with affected animals is to stamp them out by slaughtering all affected stock. The success of slaughtering policy depends on the prompt reporting of all suspected cases of the disease (Thompson and Muriel et al., 2002; Kitching and Hutber et al., 2005).

The disease is considerably less obvious in breeds of cattle indigenous to Africa and Asia including Egypt, where FMD is mostly endemic that's why the disease is so-called chronic FMD (Catley and Okoth et al., 2001). However, FMD is also economically important in these regions, further reducing an already low milk yield, causing the death in young calves and interfering with the work of adult animals (Kitching 2002).

In spite of the detailed description of FMD lesions in literatures, the frequency of their occurrence in different body regions were not considered. In addition, little attention was encountered with the topical management and medical treatment of FMD lesions. The aim of the present study is to describe FMD lesions, recording the frequency of occurrence of the lesions in different body regions and assessment of a suggested regime for treatment.

\section{MATERIALS and METHODS}

The present study was carried out on a total number of 1106 cattle (females $=935$, males $=171$ ) of an age 
varied between one and eleven years. Animals were presented to the clinic within a range of ten days of infection with different FMD lesions, history of acute febrile condition, off food, and perfuse salivation due to FMD outbreak, Abril 2012, Beni-Suef province in Egypt.

The location, extension, and distribution of the lesions were recorded for all cases. Topical and systemic treatment for all lesions were applied as follow. The results of treatment were recorded and documented.

1. Flushing of the lesions with sodium bicarbonate solution $4 \%$.

2. Trimming and freshening of the wound edges and removal of mucous membrane shreds.

3. Drying the lesions with sterile gauze.

4. Spraying for three successive days with a mixture of:

a. $200 \mathrm{ml}$ of Gentian violet $1 \%$ paint E.P. 84. $\left(\text { Gentian violet }{ }^{\circledR}\right)^{1}$ b. $100 \mathrm{ml}$ Lidocaine HCL $20 \mathrm{mg} / \mathrm{ml}$ $\left(\text { Xylocaine }^{\circledR}\right)^{2}$.

c. $250 \mathrm{ml}$ Metronidazole $5 \mathrm{mg} / \mathrm{ml}\left(\text { Flagyl }^{\circledR}\right)^{3}$.

d. $200 \mathrm{ml}$ Oxytetracycline $5 \%$ $\left(\text { Oxytetracycline }{ }^{\circledR}\right)^{4}$.

5. Single deep intramuscular injection of oxytetracycline and Flunixin Meglumine mixture $\left(\text { Hexasol } \mathrm{LA}^{\circledR}\right)^{5}$ in a dose of $1 \mathrm{ml}$ per $10 \mathrm{~kg}$ bodyweight (equivalent to $30 \mathrm{mg} / \mathrm{kg}$ oxytetracycline and $2 \mathrm{mg} / \mathrm{kg}$ flunixin).

6. Parenteral Ringer's and Dextrose $5 \%$ infusion ${ }^{6} 2$ liters of both for three successive days.

${ }^{1}$ Gentian violet-philopharm pharmaceuticals, 10th of Ramadan City -Egypt

${ }^{2}$ Xylocaine- Astra Zenece - Egypt.

${ }^{3}$ Flagyl (Metronidazol) EI-Amreia Company, Alexandria, Egypt.

${ }^{4}$ Oxytetracycline 5\% -Delta pharm - veterinary sector, 10th of Ramadan City - Egypt.

${ }^{5}$ Hexasol LA -Norbrook - Egypt.

${ }^{6}$ Ringer's and Dextrose 5\% - -ADWIC- El-Nasr pharmaceutical chemicals, Abu Zaabal, Egypt.

\section{RESULTS}

Location and frequency of occurrence of FMD lesions at different body organs were illustrated in table 1.

Table 1: Illustrates the location and frequency of occurrence of FMD lesions.

\begin{tabular}{lcc}
\hline & Location of lesion & Frequency of occurrence \\
\hline 1 & Dental bad & 1053 \\
\hline 2 & Tongue & 1020 \\
\hline 3 & Inner aspect of the lower lip & 713 \\
\hline 4 & Gum of the lower lip & 318 \\
\hline 5 & Muzzle & 104 \\
\hline 6 & Nostrils & 17 \\
\hline 7 & Hard palate & 15 \\
\hline 8 & Coronary band and interdigital space & 518 \\
\hline 9 & Teats & 303 \\
\hline
\end{tabular}

Lesions on the dental pad appear as a one or two rounded, oval or irregular ulcer with denuded mucous membrane and velvety red surface (Figure 1). Coalesce of ulcers may occur forming a large longitudinal ulcer along the whole length of the dental pad (Figure 2). Accumulation of crusts, desquamated epithelial tissues, and coagulated exudate may found covering the ulcer surface (Figure
3). Healing occurs in a form of a rounded or longitudinal pale scar, sometimes with irregular pigmentation at the center (Figure 4). Lesions of the dental bad mayinclude the inner surface of the upper lip.

Lesions of the tongue appear at the dorsal surface, less frequently affecting the lateral borders and the tip 
of the tongue, and rarely observed on the ventral surface. They appear as a row surface surrounded by ragged fragments of a loose epithelial tissues. Large shreds of mucous membrane were seen separated and detached form the underling muscles (Figure 5-6). When healing occurs, they appear as a rounded or irregular scar slightly elevated lesions (Figure 7).

Lesions at the inner aspect of the lower lipusually seen in a form of rounded, oval or irregular areas of red discoloration with denuded mucous membrane (Figure 8). Non-pigmented scar tissue was formed in treated cases. Lesions of the gum appear on the lingual and labial surfaces as irregular or oval ulcers (Figure 9).

Lesions on the muzzle appear as a one vesicle that ruptured later(Figure $10 \mathrm{~A}, \mathrm{~B})$. The whole muzzle may get inflamed and covered by desquamated and contaminated epithelial shredding (seven cases) (Figure 11 A, B). Lesions at the nostrils appear in a form of a large area of inflammatory mucous membrane with red discoloration and muco-purulant discharge (Figure 12). Rarely, Lesions were seen at the periphery of the hard palate in a form of longitudinal ulcers (Figure 13).

Separation of the claws at the coronary band with prolapse of the coronary corium were recorded and leads to a moderate degree of lameness. Thimbling of the claws was resulted and obvious1ly seen after 2 months of infection as a transverse line separating the old claws from the new ones. Slight degree of lameness due to thimbling of the claws was continued until separation of the old claws occurred few months later. Lesions of the skin at the interdigital space weredetected in 96 cases (Figure 14 A, B - 15). Multiple ulcers were also detected on the teats (Figure 16-17). Infection may develop leading to mastitis in neglected cases.

The results of topical and systemic therapy were encouraging. Recovery of all lesions on the mouth cavity wasseen within 3-10 days with variable degree of scar tissue formation. The scars appear as irregular pale de-pigmented areas on the surface of mucous membrane. The process of prehension and mastication return gradually in a parallel line with healing of mouth lesions. Slight teat dysfunction and mastitis was supervene in 33 cases. In addition, slight lameness due to thimbling of the claws was recorded in 220 animals and subsides after complete spontaneous sloughing of the old claws within 4-6 months of occurrence.

\section{Legends of figures}

Figure 1: Ulcers on the dental pad before sheading of epithelium (A) and after sloughing (B).

Figure 2: Large longitudinal ulcer along the whole length of the dental pad and at the latro-ventral aspect of the tongue.

Figure 3: A large ulcer on the dental pad before removal of desquamated epithelial tissues and coagulated exudate.

Figure 4: Healed dental pad ulcers with irregular pigmentation at the center.

Figure 5: A large area of denuded epithelium at the dorsum of the tongue.

Figure 6: A complete sloughing of the epithelial covering of the dorsal surface of the free end of the tongue.

Figure 7: Several rounded healed ulcers at the dorsum of the tongue.

Figure 8: Multiple rounded ulcers at the mucous membrane atthe inner aspect of the lower lip.

Figure 9: A. Irregular ulcers at the lingual surface of the gum of lower incisors.

Figure 9: B. Irregular ulcers at the labial surface of the gum of lower incisors.

Figure 10: A. A rounded vesicle on the muzzle before rupture (A) and after rupture (B).

Figure 10: B. A rounded vesicle on the muzzle after rupture.

Figure 11: A. Inflamed muzzle covered by desquamated epithelial shredding

Figure 11: B. Inflamed muzzle after removal of necrotic tissues.

Figure 12: Ulcers at the lateral aspect of the nostrils.

Figure 13: Irregular longitudinal ulcers at the lateral borders of the hard palate.

Figure 14: A. A separation of the claw at the level of the coronary band.

Figure 14: B. A separation of the claw at the level of the coronary band with prolapse of the coronary corium.

Figure 15: Thimbling of the claw with interdigital ulcer.

Figure 16: Multiple small ulcers at the teat.

Figure 17: Mammillitis at the four teats as a complication of FMD. 


\section{Legends of figures}

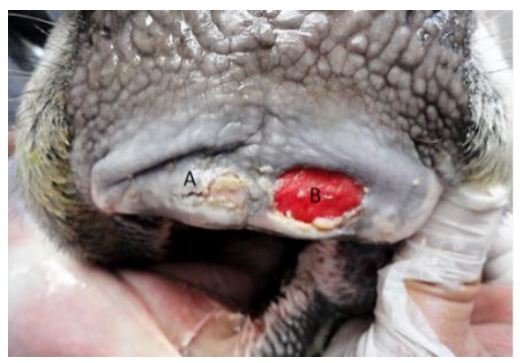

Figure 1: Ulcers on the dental pad before sheading of epithelium (A) and after sloughing (B).

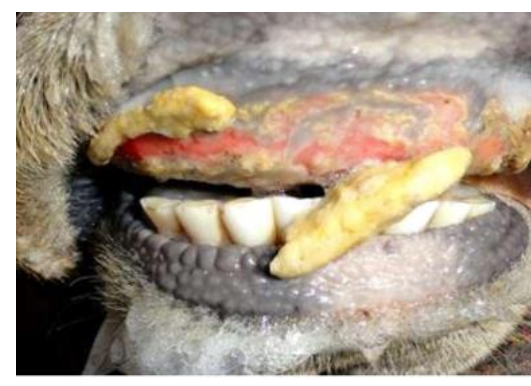

Figure 3: A large ulcer on the dental pad before removal of desquamated epithelial tissues andcoagulated exudate.

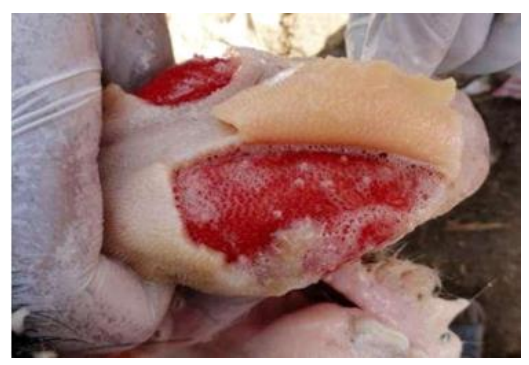

Figure 5: A large area of denuded epithelium at the dorsum of the tongue.

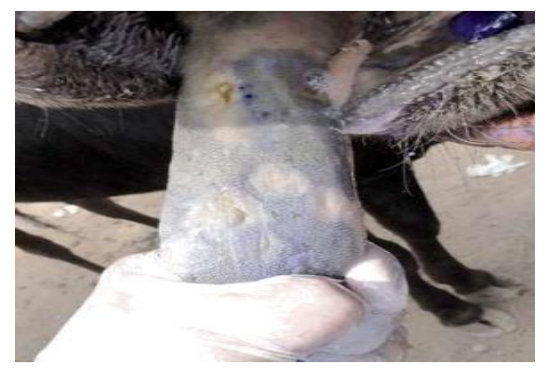

Figure 7: Several rounded healed ulcers at the dorsum of the tongue.

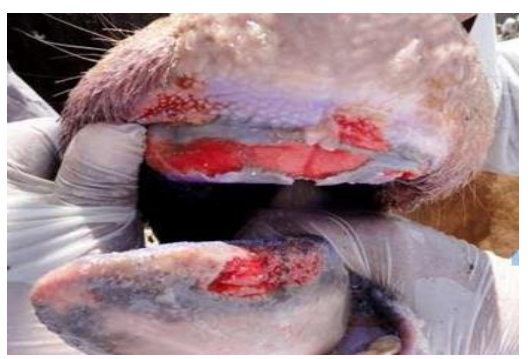

Figure 2: Large longitudinal ulcer along the whole length of the dental pad and at the latro-ventral aspect of the tongue.

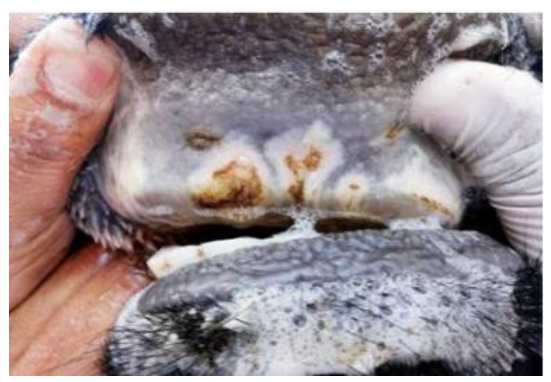

Figure 4: Healed dental pad ulcers with irregular pigmentation at the center.

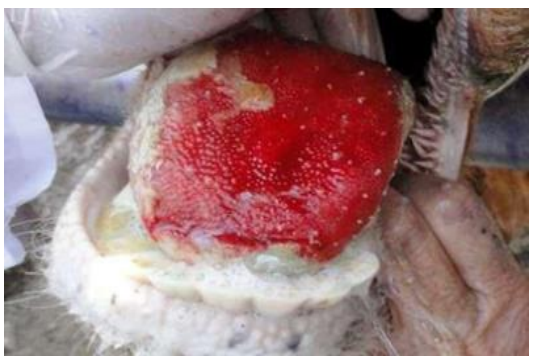

Figure 6: A complete sloughing of the epithelial covering of the dorsal surface of the free end of the tongue.

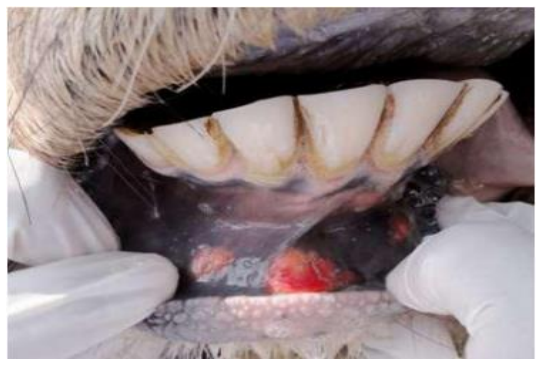

Figure 8: Multiple rounded ulcers at the mucous membrane at the inner aspect of the lower lip. 


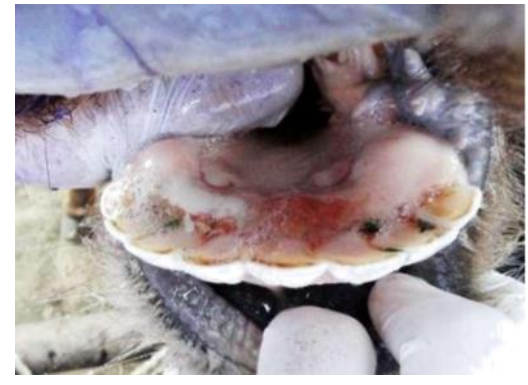

Figure 9: A. Irregular ulcers at the lingual surface of the gum of lower incisors.

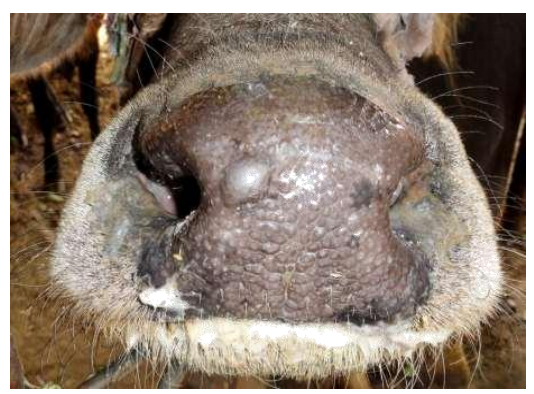

Figure 10: A. A rounded vesicle on the muzzle before rupture (A) and after rupture (B).

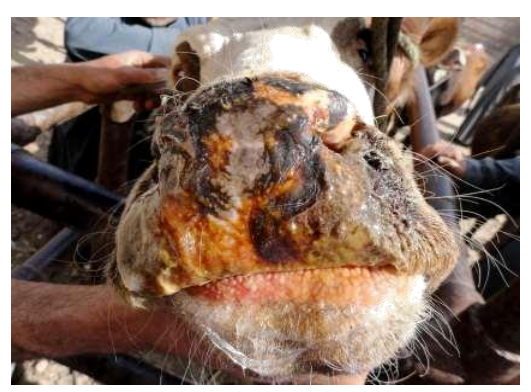

Figure 11: A. Inflamed muzzle covered by desquamated epithelial shredding

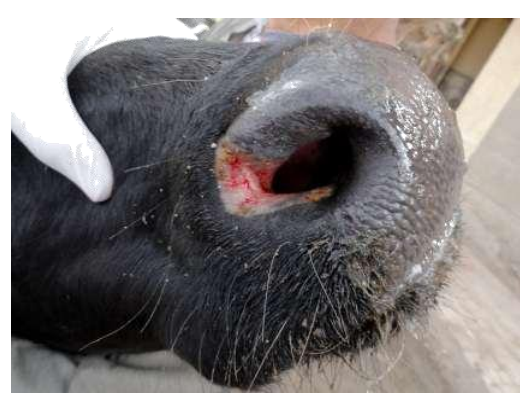

Figure 12: Ulcers at the lateral aspect of the nostrils.

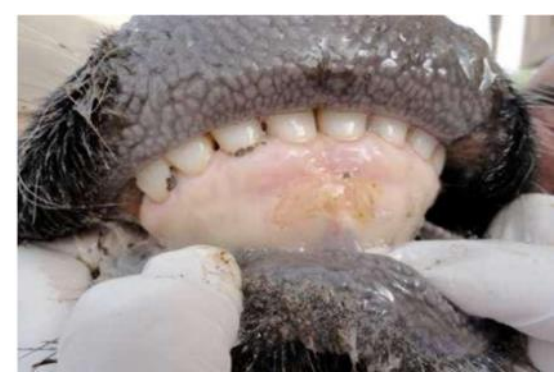

Figure 9: B. Irregular ulcers at the labial surface of the gum of lower incisors.

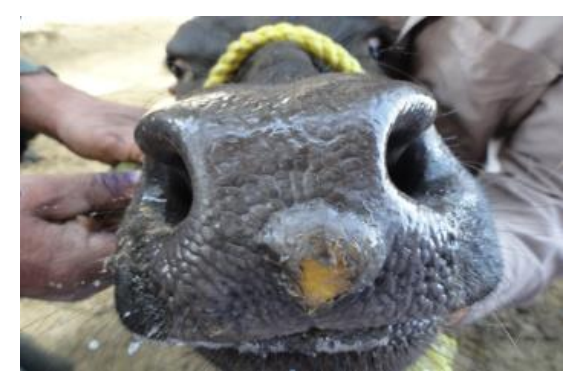

Figure 10: B. A rounded vesicle on the muzzle after rupture.

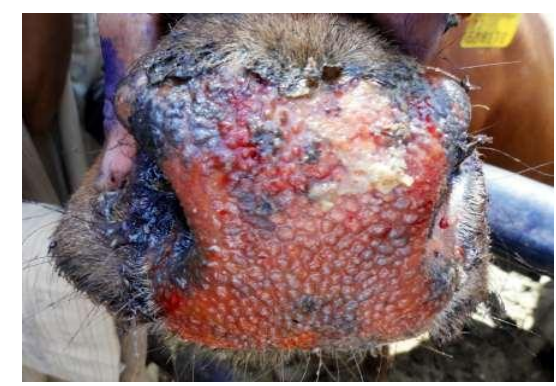

Figure 11: B. Inflamed muzzle after removal of necrotic tissues.

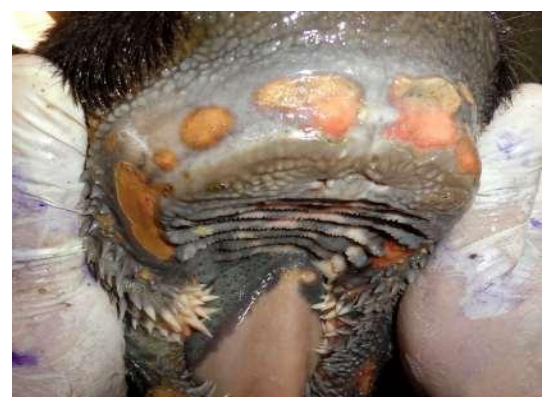

Figure 13: Irregular longitudinal ulcers at the lateral borders of the hard palate. 


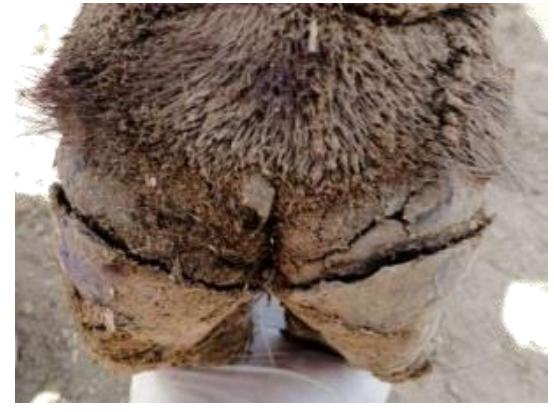

Figure 14: A.A separation of the claw at the level of the coronary band.

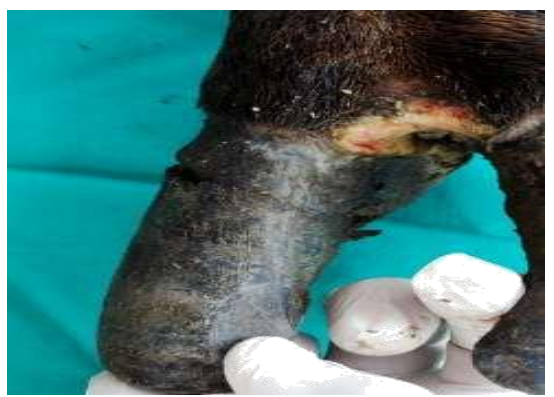

Figure 15: Thimbling of the claw with interdigital ulcer.

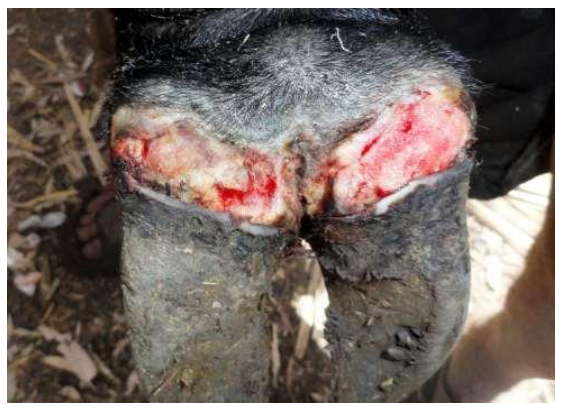

Figure 14. B: A separation of the claw at the level of the coronary band with prolapse of the coronary corium.

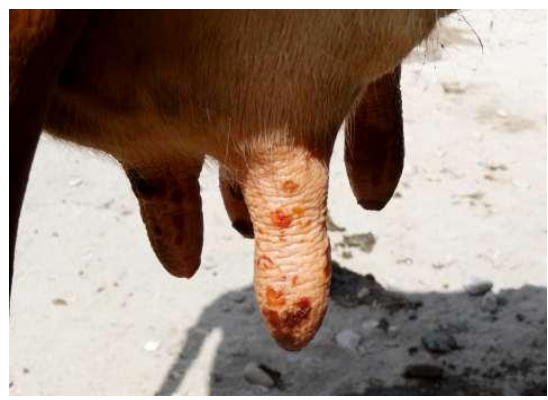

Figure 16: Multiple small ulcers at the teat.

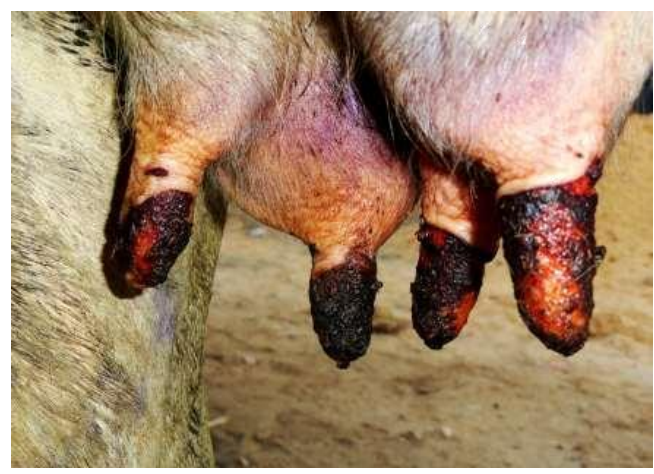

Figure 17: Mammillitis at the four teats as a complication of FMD.

\section{DISCUSSION}

Lesions of FMD were seen on the dental pad, lips, gum, and tongue and also seen on the coronary band, interdigital space, and teats (Kitching 2002). The present study revealed presence of FMD lesions at the same aforementioned locations in addition to the muzzle (104 cases), nostrils (17 cases), and hard palate (15 cases) (Alexandersen, Zhang et al., 2003).

The most commonly affected organs were the tongue, dental pad and the upper and lower lips. Moderately affected organs were the gum of the lower incisors and the coronary band. The least affected organs were muzzle, nostrils and hard palate.
Many authors due to governmental rules and regulations dealing with incoming non-endemic infectious diseases did not recommend treatment of affected animals. The policy is to stamp them out by slaughtering of all affected stock and others, which have been exposed to such risk of infection (Garner and Lack 1995; Paarlberg, Lee et al., 2002; Muroga, Hayama et al.,2012). In developing countries, where the disease is endemic, medical treatment is the economic choice.

The treatment aims to return the affected animals to normal appetite quickly and decrease the weight loss through treatment of FMD lesions at the mouth and claws as well as to prevent development of 
complications like mastitis, teat dysfunction (Sharma 2010), and lameness.

In a former study, ethnoveterinary remedies of natural soda ash solution (97\% sodium bicarbonate) with honey and finger millet flour were used to manage FMD lesions (Gakuya, Mulei et al., 2011). They reported that the fast healing of the lesions vindicates the use of these cheap locally available and easy to apply products in the management of FMD lesions. In the present study flushing of lesions with only $4 \%$ sodium bicarbonate was sufficient. Trimming and freshening of wound edges and removal of mucous membrane shreds were essential before spraying to increase the contact between the medicaments and the lesions surface. Gentian violet was applied as a topical antiseptic and Lidocaine HCL as a local anesthetic for temporary relieve of pain while Flagylto act as antimicrobial agent for anaerobes and Oxytetracycline as a topical antibiotics. In addition, systemic therapy was suggested in a form of single dose of antibiotic and anti-inflammatory. Ringer's solution and Dextrose 5\% were used to support the general condition of the animal during the first period of illness and off food. This treatment protocol was applied for all patients with good results. Only few cases developed mastitis due to late intervention with mammary gland and teat lesions. Early treatment of lesions will decrease the economic losses and speed returning the animal to normal condition.

\section{REFERENCES}

Alexandersen, S. and Zhang, Z. (2003): "The pathogenesis and diagnosis of foot-and-mouth disease." Journal of comparative pathology 129(1): 1-36.

Catley, A. and Okoth, S. (2001): "Participatory diagnosis of a chronic wasting disease in cattle in southern Sudan." Preventive veterinary medicine51(3): 161-181.
Davies, G. (2002): "Foot and mouth disease." Research in veterinary science73(3): 195-199.

Gakuya, D. and Mulei, C.M. (2011): "Use of ethnoveterinary remedies in the management of foot and mouth disease lesions in a diary herd." African Journal of Traditional, Complementary and Alternative Medicines $8(2)$.

Garner, M.G. and Lack, M. (1995): "An evaluation of alternate control strategies for foot-and-mouth disease in Australia: a regional approach." Preventive veterinary medicine 23(1): 9-32.

Kitching, R. (2002): "Clinical variation in foot and mouth disease: cattle." Revue scientifique et technique-Office international des épizooties 21(3): 499-502.

Kitching, R.P. and Hutber, A. (2005): "A review of foot-and-mouth disease with special consideration for the clinical and epidemiological factors relevant to predictive modelling of the disease." The Veterinary Journal169(2): 197-209.

Muroga, N. and Hayama, Y. (2012): "The 2010 footand-mouth disease epidemic in Japan." Journal of Veterinary Medical Science74(4): 399-404.

Paarlberg, P.L. and Lee, J.G. (2002):"Potential revenue impact of an outbreak of foot-andmouth disease in the United States." Journal of the American Veterinary Medical Association 220(7): 988-992.

Sharma, N. (2010): "Foot and mouth disease-Mastitis cascade in dairy cattle: A field study." International Journal of Zoological Research 6(4): 356-359.

Thompson, D. and Muriel, P. (2002): "Economic costs of the foot and mouth disease outbreak in the United Kingdom in 2001." Revue scientifique et technique-Office international des épizooties 21(3): 675-685.

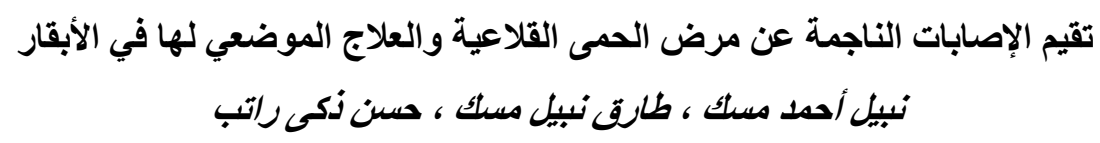

Email: tarik.misk@vet.usc.edu.eg

Assiut University Email: www.aun.edu.eg

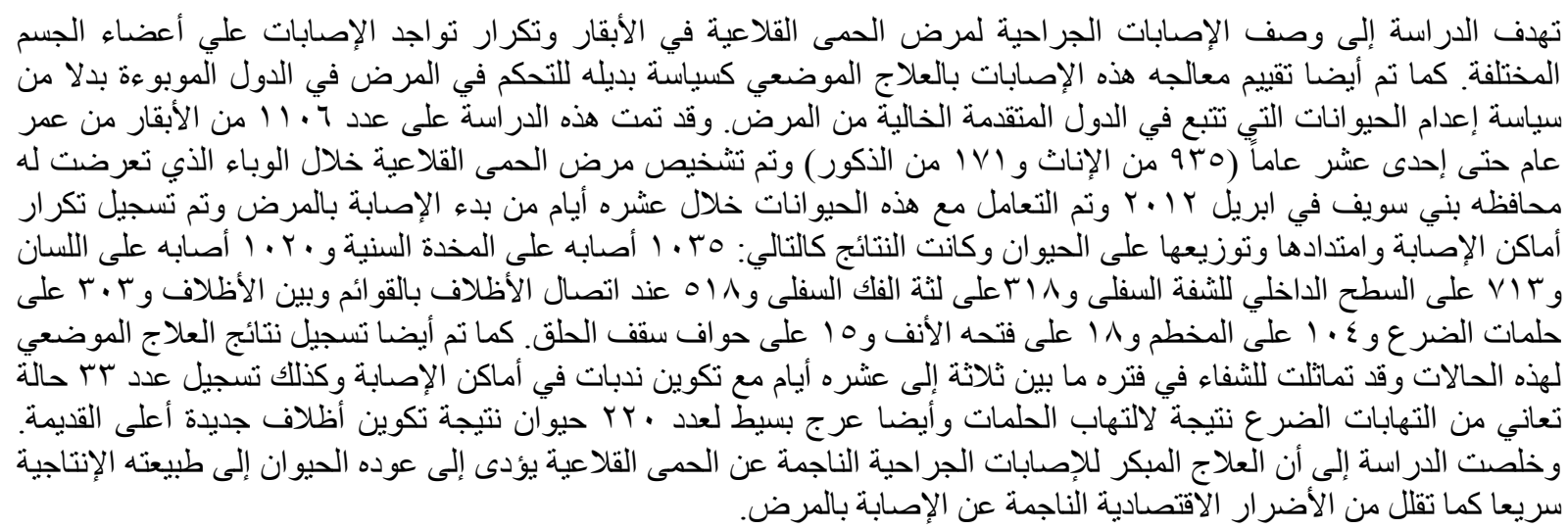

